\title{
HERRAMIENTAS PARA LA PREVENCIÓN DE LOS DELITOS DE ODIO CONTRA LAS PERSONAS O GRUPOS DE PERSONAS POR RAZÓN DE RELIGIÓN O DE CREENCIAS
}

\author{
Irene M. BRIONES MARTÍNEZ \\ Departamento de Derecho Internacional, \\ Eclesiástico y Filosofía del Derecho \\ Facultad de Derecho. \\ Universidad Complutense de Madrid \\ iremar@der.ucm.es
}

\section{PRIMER BLOQUE. HERRAMIENTAS DE PREVENCIÓN DEL DELITO DEL ODIO Y DEL TERRORISMO}

En la Recomendación 1805 (2007) de la Asamblea Parlamentaria del Consejo de Europa se afirma que la blasfemia no debe considerarse un delito, pero sí conmina a las legislaciones nacionales para que castiguen el delito de odio. Las leyes que regulan el delito de blasfemia se han ido derogando; algunas sobreviven, pero únicamente sobre el texto o el papel, y tienen una escasa influencia en la interacción entre la libertad de expresión y las ofensas contra la religión, y lo mismo ocurre con la denostada difamación de las religiones. Los casos se dilucidan normalmente por la vía del hate speech, salvo supuestos como Finlandia con el delito del breach of the sanctity of religion, la blasfemia maliciosa de Grecia, la ley de blasfemia en Irlanda o la ley rusa que sanciona con tres años de prisión la blasfemia (tras el suceso del grupo de música punk Pussy Riot), entre otros países especialmente islámicos, pero en general, se procura que no haya distinción entre religiones celestiales (monoteístas-abrahámicas) y no celestiales, como ocurría en Turquía antes de declararse inconstitucional por quebrantar el principio de igualdad, ya que la igualdad y la no discriminación, así como la libertad de expresión, ahora parecen tener más fuerza legal que la libertad de religión descrita por Silvio Ferrari como «bella e impossibile» al analizar el caso de Boca Ratón en Florida. 
Para acercarnos al delito y el discurso de odio tenemos que mencionar la Recomendación (97) núm. 20, del Comité de Ministros de los Estados Miembros del Consejo de Europa, en la que se muestra una gran preocupación por el resurgimiento actual del racismo, la xenofobia, el antisemitismo y el desarrollo de un clima de intolerancia, por lo que se invita a un compromiso para combatir todas las ideologías, políticas y prácticas que constituyen una incitación al odio racial, la violencia y la discriminación.

La Comisión Europea contra el Racismo y la Intolerancia (ECRI), en su Recomendación de política general núm. 15, establece la medidas para la lucha contra el discurso de odio, entre las que se encuentra la invitación a la firma del convenio contra la ciberdelincuencia y se recomienda que se retire cualquier tipo de reserva al art. 20 del Pacto Internacional de Derechos Civiles y Políticos sobre la lucha contra la apología del odio.

La legislación penal española suscribe el acuerdo de uso del término de odio en el ámbito de la OSCE, tras ser aprobado en 2003 por este organismo internacional que reúne a 55 países durante el Consejo de Ministros de Asuntos Exteriores de Maastricht. Recordemos, además, que la OSCE elabora cada año un informe sobre crímenes de odio.

El informe de la Comisión de Venecia (2008) se preocupó especialmente por la incitación al odio religioso. Examinada la legislación europea sobre blasfemia, insultos e incitación al odio religioso, concluye que la incitación debería ser objeto de sanciones penales, especialmente si hay intencionalidad o imprudencia; esta propuesta, según algunos autores como Paul Coleman, se introdujo por las reivindicaciones soviéticas de la facultad del Estado para censurar el discurso a través del Derecho penal en las negociaciones sobre el art. 4 de la Convención sobre la eliminación de toda forma de discriminación racial.

Aunque, debemos matizar, que la Comisión considera que no debe ser objeto de sanción el simple insulto a los sentimientos religiosos y que la blasfemia debería abolirse.

A este informe le sigue el Plan de Acción de Rabat sobre la prohibición de la apología del odio nacional, racial o religioso que constituya incitación a la discriminación, hostilidad o violencia» emitido por las Naciones Unidas de 5 de octubre de 2012, en el que se recalca la necesidad de las prohibiciones penales.

En general, el delito de odio, incluso en forma de discurso, implica la incitación, la violencia y la discriminación contra personas o grupos de personas por razón de su religión o creencias, pero no directamente para proteger a la religión o a las creencias, sino a las personas. Delito que afec- 
ta en el ámbito de Estrasburgo al art. 10 del Convenio y al art. 17 por la conocida doctrina negacionista o de la guillotina, jurisprudencia de la que trato en mi proyecto de investigación a lo largo de cuarenta páginas y en la que parece que sus argumentos censores crean una nueva libertad: «la libertad de no ser ofendido». En otros continentes también contemplamos estos itinerarios, aunque con diferentes peculiaridades.

Entre el discurso del odio religioso o contra la religión vemos una conexión con el terrorismo. En efecto, en el terrorismo, el odio y las emociones están en el comportamiento y en el lenguaje derogatorio y exterminador. En el terrorismo, la religión es el problema y la víctima. Los ataques terroristas han desencadenado consecuencias negativas como la situación de «ansiedad» en la imposición de medidas de seguridad nacional, con detenciones ilegales, como lo afirma la reciente sentencia Mehmet Hasan Altan c. Turquía, de 20 de marzo de 2018, con la intromisión en la intimidad y la vida privada, y otras violaciones de los derechos humanos, como la propuesta de cámaras de video vigilancia en los lugares de culto islámico, tras la SAN 6/2005, de 26 de septiembre, en la que se advierte que las mezquitas son utilizadas como lugares de reunión de fundamentalistas islámicos para difundir sus doctrinas y reclutar adeptos para la Yihad.

Empero también se producen consecuencias positivas como la prohibición de libros que promuevan la Yihad, como el libro «Defence of Islamic lands and join the Caravans» en Australia, o en Indonesia: «I fight terrorist». En estos supuestos más que una medida de seguridad nacional que limita la libertad de opinión, la libertad de expresión y la libertad religiosa, es una medida de protección de los derechos humanos, aunque algún autor critique la mayor censura de la libertad de expresión y el incremento de las medidas de seguridad, porque incluso obedecer la ley no será garantía de que el Estado te deje en paz.

En esta misma línea se encuentra la lucha contra la ciberdelincuencia como se advierte en la Resolución del Parlamento Europeo de 3 de octubre de 2017; igualmente la Sentencia del Tribunal Supremo de 17 de noviembre de 2017, en la que se confirma que retuitear mensajes que enaltecen el terrorismo también es delito, o la pena privativa de libertad en noviembre de 2016, para el tuitero que dijo que no le daba pena Miguel Ángel Blanco. Del mismo modo, la necesaria limitación de la libertad de asociación tal y como se desprende de la STEDH Vona c. Hungría, de 9 de junio de 2013, asimismo la retirada de apoyo financiero a fundaciones o a cualquier asociación que pueda estar ligada a actividades terroristas, aunque también persigan fines sociales y religiosos, o solo cuando ataquen el patrimo- 
nio cultural o trafiquen con bienes culturales, lo que ha motivado Resoluciones del Consejo de Europa como la de 2199 (2015), y la 2322 (2016). Y, como se recomienda también en la Declaración ministerial sobre la prevención y la lucha contra la radicalización que conducen al extremismo violento, celebrada en Belgrado (2015) por la OSCE, en la que se condena firmemente la destrucción del patrimonio cultural y de lugares religiosos.

En definitiva, aunque las bombas de Nagasaki e Hiroshima quedan comprendidas dentro de lo que conocemos como War of Terrorism, el terrorismo de Charlie Hebdo, las torres gemelas y tantos otros ataques también son crímenes y no se protegen como expresión de la libertad religiosa.

Señores, el terrorismo religioso está influyendo en el estatus de la libertad religiosa.

\section{Primera herramienta: la necesidad de contar con la fe para sostener la debilitada vitalidad de la conciencia democrática en un mundo global}

Si tomamos la temperatura a la religión en el siglo XXI, podemos comprobar que la religión no está muerta en este mundo global, y que frente a una sociedad civil compuesta por la esfera privada y la pública, entre otros aspectos, también encontramos a la religión como una dimensión de la sensibilidad espiritual y moral de la sociedad, un valor público.

El crecimiento de los grupos religiosos y de las creencias se ve limitado en un campo estéril como es el de una sociedad moderna, sin embargo, las libertades personales y las elecciones de conciencia se abren paso con más fuerza, y también los grupos cuando se sienten presionados por la hostilidad del laicismo: «When you put a cat into a corner, it might turn around as a tiger».

Aunque el secularismo de la Ilustración fuese inspirado como un sustituto o el reemplazo de la religión como fuerza central en la sociedad, y hoy en día, muchas de las tradiciones religiosas tengan un sabor secular, en realidad lo religioso y lo secular coexisten en muchos aspectos de la vida pública. Es más, podríamos contemplar a la religión como una especie de termómetro de una sociedad que se rompe, como una alternativa.

Pasados los siglos, la religión vuelve a reentrar en la vida pública, pero no de modo monolítico sino con la fuerza de la diversidad. 
En algunos sistemas jurídicos, hay una conciencia creciente del pacto con la diversidad. El conflicto aparece cuando unos países castigan a las minorías, o cuando los mismos grupos religiosos tienen encuentros salvajes, sumidos en una caótica transformación de la sociedad globalizada.

La globalización es como un asalto. Un asalto a la identidad estatal y a su sociedad, y un asalto a las personas que cambian de territorio pero no de creencias y tradiciones, que como equilibristas saben que hay una red que les espera por si caen, llamada globalización, pero prefieren mantenerse sobre la cuerda para no perder su identidad, lo que produce una gran tensión, y una continua sensación de caída al vacío.

Esta tensión hace que en el anverso del potencial inmenso de paz e integridad de la religión encontremos su lado oscuro, el de la venganza irracional frente a los ataques de la corrupción de la libertad de expresión. Sin embargo, esta corrupción proviene a veces de los mismos líderes religiosos. Uno de los telepredicadores egipcios más conocidos es Ahmed Abdallah, que llegó a los titulares internacionales en 2012 cuando destrozó una Biblia cristiana ante la embajada de los Estados Unidos, en protesta por la película La inocencia de los musulmanes, considerada un ataque feroz contra el profeta Mahoma y sus seguidores.

Los musulmanes generan mayor expectación, pero también otras religiones utilizan la violencia. Así el extremista cristiano Terry Jones, un pastor de Florida, que quemó públicamente una copia del Corán, infundiendo una furia global. También es conocido el evangelizador Pat Robertson que describe públicamente al Islam como demoníaco.

Ahmed Abdallah y Terry Jones son hombres educados en la Universidad, en la generación del Facebook y del tuit, que participan en shows televisivos, y no simples líderes que predican en sus templos a sus feligreses. A pesar de su formación universitaria, no han conseguido una equilibrada conciliación entre fe y razón, de modo que precisamente su cualificación profesional potencia la capacidad de dañar y manipular las conciencias, con estrategias de poder.

Entre los hombres de Estado, están los que agreden a la religión con hostilidad. Concretamente, los musulmanes se sitúan como «los otros». También hay otros gobernantes que gestionan la diversidad religiosa como una riqueza, una reto apasionante que ha revolucionado la historia de las últimas décadas.

Entre los hombres de fe, encontramos a aquellos que aman la libertad religiosa y el diálogo entre las religiones, y también los que luchan con armas peligrosas para defender su identidad y tradiciones fren- 
te a un mundo global, de relativismo, de múltiples opciones ante el mismo interrogante.

Llegados a este punto, ya sabemos que la globalización no solo se refiere únicamente al impacto sobre la economía y los negocios, sino a las personas cuyo bagaje es inherente y ante un espectro de múltiples identidades se desorientan, desarrollan ansiedad y puede reaccionar de diversos modos:

a) la marginación o guetos, intentando desintoxicarse de Occidente, del imperialismo cultural, con vidas apagadas en continua defensa de las cámaras de gas tóxico que ofrece Occidente, o con vidas resentidas que se entregan a la causa de vengar a Alá.

b) La reinvención de la propia religión en un territorio diferente. Se produce la integración, creando redes sociales a través de sus comunidades religiosas. La religión crea un network entre las personas de la misma cultura religiosa y se construye capital social.

Ante esta bifurcación, aparece la conocida teoría de la religión global, teniendo en cuenta que las tradiciones religiosas atesoran grandes confluencias e intersecciones a lo largo de la historia, de modo que podríamos crear una ciudadanía global construida sobre un consenso moral. Cox, Bellah o Habermas, abogan por encontrar un denominador común en las religiones, y no sería difícil, pensemos en la caridad y la compasión, pero las olas a veces desbordan las orillas serenas y tranquilas, con actos terroristas de los musulmanes o, por el contrario, ataques de budistas a los musulmanes como en Myanmar, ejemplos que impiden mantener vivo un solo corazón para todas las religiones.

Por este motivo, se reivindica la privatización de la religión operada por la Ilustración, e incluso algunos van más allá reivindicando que se proteja el ámbito privado del fundamentalismo obscurantista. Mientras la esfera pública sería un ámbito abierto, liberal, secular, donde la libertad de expresión y la razón pública predominan.

De modo que un sector de intelectuales sugiere que la religión debería morir y reemplazarse por el arte y la ciencia, que satisfacen la necesidad por la devoción, la pasión y la esencia o el significado de las cosas.

En el marco del relativismo en el ejercicio de la libertad de expresión para ofender, y en la degeneración de la libertad religiosa para matar al infiel, sin respetar su libertad de conciencia ni su vida, me viene a la mente el diálogo entre Ratzinguer y Habermas. 
Desde la filosofía de Habermas, el respaldo de las instituciones ya no puede ser religioso o metafísico: debe ser racional.

Ratzinger contraataca manifestando que los valores firmes no surgen de los caprichos personales del individuo ni pueden fundarse siempre de manera racional o democrática. Esto último es claro en el ejemplo de los derechos humanos. ¿Acaso las mayorías que votaron y llevaron legalmente a Hitler al poder en Alemania hubieran consagrado la dignidad humana?, arguye Ratzinger. Hay valores que se sostienen por sí mismos, sin necesidad de argumentos o consensos. No es sensato postrarse ante el fetiche del yo moderno ni el de sus mayorías. Estas no siempre tienen razón.

Es cierto que Habermas se muestra preocupado por los temas de siempre, pero a la vez, y esto es sorprendente en quien al pasar se define como indiferente — «sin oído musical para la religión»- insistió en la necesidad de contar con la fe para sostener la debilitada vitalidad de la conciencia democrática.

Este diálogo entre grandes pensadores debería sustituir por un lado, al mediocre discurso populista de algunos gobernantes, de la prensa y de los medios de comunicación en general, y por otro, a la cruel imagen de un Creador que destruye y aniquila, transmitida por los fundamentalistas.

\section{Segunda herramienta: la mejor calidad de la educación y la socialización (inclusión social e integración)}

Tras la invasión de Afganistán por las tropas americanas y de los países aliados, cientos de jóvenes musulmanes, a los que se consideraba enemigos combatientes, fueron internados en prisiones, sometidos a duros interrogatorios con técnicas que incluía aplicarles descargas eléctricas con electrodos puestos en sus genitales, clavarles astillas en la intersección de las uñas, mientras se divertían haciendo mofa de sus creencias religiosas.

En la ciudad de Oslo, Andrés Breivick, un lobo solitario, sin antecedentes penales, y con un buen nivel cultural y económico, de clara ideología ultraderechistas y racista, que acusaba al gobierno de haberse vendido al Islam, llegó a la isla de Utoya y mató a 77 personas. Un grupo de expertos psiquiatras dictaminó que sufría de psicosis esquizofrénica paranoica y, posteriormente, otro grupo de psiquiatras afirmo que no padecía enfermedad alguna y era plenamente responsable de sus actos.

Antonio, hombre agresivo y con antecedentes penales, entra en una Iglesia, se desplaza hasta el primer banco y dispara directamente a la cabe- 
za de una mujer en avanzado estado de gestación, acto seguido se coloca frente al altar, se arrodilla y se pega un tiro en la boca. No había ninguna relación entre Antonio y su víctima.

Lo primero que pensamos sobre los asesinos en estas tres historias es que hay «algo roto en su interior».

Lo que el Derecho, la Religión y las políticas en materia de prevención del delito de odio puedan hacer, dependerá del autor del delito.

En la investigación de las medidas preventivas para evitar los delitos, nos encontramos con los delincuentes natos, de modo que podríamos negar la culpabilidad individual y el libre albedrío.

Ahora bien, donde se produce una mayor vinculación con la delincuencia es en el concepto de personalidades psicopáticas, que no pueden incluirse ni en la psicosis ni en la neurosis, sino en una forma anormal de la formación de la personalidad, entre las cuales se clasifica a los fanáticos, y suelen ser desalmados, y carecer de compasión.

Un grave trastorno de la personalidad, que no es una enfermedad mental, suele ser el origen de comportamientos criminales, y se encuentran en mayor o en menor grado en los terroristas y los «serial killers», aunque en los primeros suele darse un componente ideológico o religioso, que no se da en los segundos.

También existen factores externos al individuo que condicionan su comportamiento, y es aquí donde se aplica la teoría de la socialización deficiente. En este caso se trata de una conducta criminal aprendida por la experiencia vital del sujeto.

Así que deberíamos preguntarnos si es cierta la teoría de algunos médicos forenses cuando afirman que las sociedades tienen los delincuentes que se merecen, si se respira la corrupción de la libertad de expresión y la violación de los derechos fundamentales o se practica la tortura en las instituciones penitenciarias, es posible que se busquen puntos firmes de sujeción como una creencia religiosa, que manipulada por otros afanes en el contacto, la interacción con otros individuos, produce una desviación en la conducta.

Si hablamos de una conducta aprendida, resulta más factible que sea igualmente desaprendida, de ahí que sea necesaria la reintegración, la justicia restaurativa y la mejora de la calidad en la educación para la formación de la personalidad.

Aun así, en este último supuesto, no resulta fácilmente manejable la prevención del delito de odio puesto que estamos, no ante subculturas separadas de la cultura dominante, sino de «culturas alternativas» o sociedades paralelas que el Estado no sabe cómo neutralizar porque en el caso de ape- 
lación a instancias superiores como las creencias religiosas, se niega lo injusto del actuar, se rechaza a la víctima, el terrorismo se convierte en una especie de guerra santa, los radicalizados se definen además como born again, un terror que invoca al cielo, un martirio repugnante a la razón.

\section{Tercera herramienta: tribunales religiosos y arbitraje religioso}

Estas culturas alternativas son las que reivindican los tribunales religiosos, el pluralismo jurídico. En efecto, estos tribunales pretenden instalar el pluralismo jurídico de Santi Romano, la coexistencia de ordenamientos jurídicos cada uno con su propia competencia, y algunas se topan con el «one law for all» para evitar conductas ajenas a la visión occidental de los derechos humanos que constituye la cultura dominante, como la poligamia, el repudio, la dote, la custodia de los hijos, la herencia de menores según el sexo, y otros asuntos similares, lo que supone una actitud dotada de gran hipocresía ya que por vía del Derecho internacional, sí se aceptan como procedentes de otros regímenes jurídicos.

Teniendo su domicilio en un país no islámico, solo les queda hacer uso de las leyes de arbitraje, y también colisionan con el «one law for all» como en Canadá, a pesar del informe Boyd, ante todo se protegen los derechos humanos de las personas como ciudadanos, sean o no creyentes. Ahora bien, también los miembros de confesiones menos sospechosas no pueden alterar lo previsto en ordenamientos estatales.

\section{Cuarta herramienta: sana y moderada implicación entre el Estado y la religión}

En estas culturas alternativas hay un grupo de individuos, buenos ciudadanos y buenos fieles que necesitan solucionar sus problemas de conciencia, y piden pactos en materia de interés mixto, y/o el reconocimiento de tribunales religiosos para conflictos matrimoniales u otras causas, así como una legislación unilateral que reconozca el ejercicio de sus creencias por su condición de personas. Los sistemas matrimoniales que también entran en el ámbito del pluralismo jurídico dependen del modelo de relación entre Estado e Iglesias, de separación, de cooperación, y de Iglesia nacional. Este último ya en declive como es el caso de Suecia, Noruega, los países de fuerte tradición Luterana, e incluso los ortodoxos van 
suavizando sus regímenes. Hasta la Iglesia de Inglaterra utiliza sus prerrogativas y poder político para favorecer el pluralismo religioso. Tampoco hay un régimen puro de separación ni siquiera en Francia, se ha producido una convergencia del extremismo al centro, una implicación moderada con la religión por parte de los Estados laicos que también puede ser una herramienta para la Paz y la Tolerancia Religiosa que prevenga el delito de odio.

En las mismas culturas alternativas, hay otro grupo de individuos que un 13 de noviembre de 2015 hicieron más de 600 disparos de klashnikov. En esta ocasión, las víctimas no eran enemigos declarados, ni musulmanes apóstatas ni periodistas, como en la matanza de Charlie Hebdo, pero sí son infieles en un país que ha prohibido el uso de símbolos religiosos, como es el caso de Francia y Bélgica.

Estos distintos grupos de individuos de una cultura alternativa a la dominante como es el Islam, no debe propiciar una separación hostil entre el Estado y la Religión, se recomienda una relación moderada y neutral, que la longa manus de la laicidad positiva y negativa, haga factible la visibilidad del ejercicio de derechos fundamentales y libertades públicas, porque de lo contrario estaríamos ante unas leyes parecidas a las que se dictaron en la época de la dictadura española, por las que se trataba al ciudadano como un criminal antes de cometer un delito, porque su condición se consideraba predeterminante de su criminalidad futura, como es el caso de la vagancia o la homosexualidad.

\section{SEGUNDO BLOQUE. RETOS DE LAS RELIGIONES Y EL ESTADO PARA PREVENIR EL DELITO DE ODIO}

\section{Primera herramienta: el diálogo interreligioso y la mediación}

Bajo el auspicio de la Alianza de Civilizaciones de Naciones Unidas y el Centro Norte-Sur del Consejo de Europa, se celebró el Foro de Lisboa en 2010, dedicado a la libertad de expresión, de conciencia y de religión. En sus conclusiones se ha subrayado que el diálogo interreligioso es un elemento esencial del dialogo intercultural. Una sociedad democrática debe autorizar en nombre de la libertad de pensamiento y de expresión, un debate abierto a cuestiones relativas a las creencias y a la religión.

Quizá por este motivo, en las conclusiones del Consejo de Europa sobre prevención de la radicalización que conduce al extremismo vio- 
lento 2016/C467/02, se invita a fomentar y respaldar la investigación y el aprendizaje entre iguales de los profesores, educadores y demás personal docente, expertos y responsables políticos para poder permitir la puesta en común de buenas prácticas y adquirir una mejor comprensión del problema de la radicalización, que conduzca a un marco político idóneo.

En Italia se está realizando una labor importante de carácter universitario. Hablamos del International Forum on Religions and Democracy que combina la investigación académica con acciones sociales significativas. Fue creado en 2009 y es un consorcio formado por cinco universidades del norte de Italia. Su trabajo consiste en la transferencia de herramientas a los musulmanes, o de reforzar las que ya tienen, mediante procesos de mediación y diálogo con las instituciones y la sociedad. Se intenta desarrollar buenas y mejores prácticas. En sus programas se incluye a más de 40 representantes y líderes religiosos de primera y segunda generación, que son mediadores para encajar los códigos de conducta entre la sociedad islámica de origen y la host society, la anfitriona y receptora. Esta labor a través de la Mediación, se ejecuta como Herramienta de Paz y para el efectivo reconocimiento de la libertad religiosa que puede prevenir el odio.

Los musulmanes nacidos en países laicos, pueden ser coautores de la sociedad occidental y de la democracia como se afirma en la Recomendación de la Asamblea Parlamentaria del Consejo de Europa 1396 (1999), Religión y Democracia, aprendiendo a trabajar en sociedades abiertas y democráticas. Una de las herramientas para la construcción de esta coautoría es el tener líderes religiosos educados en territorio occidental, en vez de líderes importados que puedan transmitir una considerable tensión entre la conservación de la identidad y la adaptación a una cultura más ancha de miras. A cambio, el sueño occidental, los sistemas democráticos deben proteger sus derechos fundamentales, con serias exigencias de tolerancia consensuada por los poderes públicos.

Fuera de la acción civil, el Pontífice como líder religioso también contribuye a la Paz. Lo hizo en su visita a Tierra Santa en 2014 como encuentro de tres grandes religiones, en su visita a Asís para la Jornada Mundial de oración por la Paz «Sed de Paz. Religiones y Culturas en Diálogo», el 20 de septiembre de 2016, y en sus últimas visitas de 2017 y 2018.

En la línea del Religious peacebuilding, en agosto del año 2000 tuvo lugar el Millenium World Peace Summit of Religious and Spiritual Peace. Se reconoce que a menudo la religión ha sido utilizada para enfrentamientos violentos e invita a cultivar una auténtica cultura de paz como fruto de tradiciones religiosas y espirituales. 
Las religiones se han ocupado de celebrar algunos Congresos del Parlamento de las Religiones, que nació en Chicago. En estos Congresos se pueden encontrar algunas herramientas de prevención del delito contra la persona o grupos de personas por razón de religión o creencias: la potenciación del diálogo interreligioso mediante el conocimiento de las religiones; compromiso por la paz y de no sacralizar la violencia; considerar iguales a los hombres y mujeres; compromiso de defensa de la vida y de la naturaleza; respeto por la libertad religiosa, la apostasía, el ateísmo y sus razones; responder a los grandes interrogantes antropológicos conciliando fe y razón; promover el sentido de la alteridad y la diferencia; adoptar una actitud de autocrítica, para no caer en la autocomplacencia; y respetar las competencias estatales.

Mientras las religiones deberían ocuparse de utilizar estas herramientas, ¿qué hace el Estado?

Quizá deberíamos potenciar, como se hace en los Países Bajos, el diálogo a través de plataformas interreligiosas y de los Consejos de Iglesias que se relacionen con el Parlamento y el Gobierno.

Por si alguien piensa que en España se actuaría de modo diferente a como lo hizo la justicia francesa en el conflicto de Charlie Hebdo, pues bien, aun siendo el odio un agravante de cualquier delito contra las personas, y de configurarse los delitos de odio tras las reformas del Código penal, siguiendo la Decisión Marco de la UE (2008/913/JAI), relativa a la lucha contra el racismo y la xenofobia mediante el Derecho penal, hemos sido testigos de cómo se absuelve a Rita Maestre, mientras se crucifica a nivel mediático a los ministros de culto por su opinión sobre la homosexualidad, aunque exonerándolos judicialmente si se sigue literalmente la ortodoxia en ejercicio de su libertad religiosa, con la misma controversia judicial y mediática como el caso Ake Green en Suecia.

Habría entonces que preguntarse por las herramientas de compromiso por parte de la sociedad y del Estado: donde está la potenciación del diálogo entre lo secular y lo sacro; dónde está el compromiso por la paz y de no sacralizar la violencia de palabra o de imágenes en sus múltiples vehículos de transmisión; dónde está la creación de redes de solidaridad y trabajo por un orden internacional justo donde los emigrantes o simplemente los diferentes se puedan acomodar sin tensiones ni mofas ni burlas; dónde está la práctica de la tolerancia y del diálogo fuera del papel de los pactos con algunas religiones; dónde está el compromiso de defensa de la vida y también de la naturaleza; dónde está el respeto por la libertad religiosa, tanto como se respeta el ateísmo y sus razones; dónde está la respuesta a los 
grandes interrogantes conciliando libertad y razón; dónde está el ejercicio de una función terapéutica en la curación de los conflictos entre conciencia y ley de los ciudadanos y fieles; dónde está la promoción del sentido de la alteridad y la diferencia cuando se trata de culturas alternativas; dónde está la adopción de una actitud de autocrítica, para no caer en la autocomplacencia política; y donde está el deber de no sacralizar ideologías estatales.

\section{Segunda herramienta: educación en la religión y en las religiones}

El Estado tiene grandes retos, como hemos visto. La educación es una de las herramientas que ayuda a formar la personalidad y evitar conductas criminales, también la educación moldea la parte sociable del menor, y le hace madurar su sentido de la alteridad. Además, en la educación se ejerce la libertad religiosa del menor y de sus padres.

$\mathrm{El}$ acoso escolar, el bullying, y el ciberacoso de menores son indicadores de una educación deficiente; las convicciones pueden ser motivo para cometer un crimen o ser víctimas del odio ya en la más tierna infancia.

Efectivamente, desde la infancia nos convertimos en agresores, la interacción escuela-familia no funciona, y desde esta plataforma podemos vislumbrar que siendo adultos, la libertad de expresión y el discurso del odio vayan de la mano, que la libertad religiosa y la violencia no encuentren un punto intermedio en el camino llamado tolerancia.

La educación «en la religión», como afirma UNESCO, es una buena apuesta por la libertad religiosa y la colaboración con la familia, para prevenir el odio hacia lo diferente.

También las asignaturas alternativas que nos introducen en el conocimiento de otras religiones.

Lo mismo podemos decir de las asignaturas que proponen una ética común, o educación en valores. En vista de la dificultad de un consenso sobre la base de esta ética, y del posible adoctrinamiento estatal deberían concederse exenciones a las sinceras opciones de conciencia de los padres.

La educación para la ciudadanía o esta asignatura introducida en otras transversales solapadamente, no representaría un problema si no fuera por los lobbies que empujan hacia el adoctrinamiento estatal. Una vez erosionado el consenso que la tradición suscitaba, se practica «la administración moral democrática dependiente del poder político» $\mathrm{y}$, como todo poder, necesitaría de mediaciones como la familia, el contexto sociocultural, y las religiones y, en concreto, la educación en la religión. 


\section{Otras herramientas: la equilibrada ponderación judicial y la tolerancia entre las propias religiones}

El equilibro entre libertad religiosa y libertad de expresión aparece como una lucha entre derechos humanos: buman rights versus buman rights.

El art. 10 del Convenio Europeo de Derechos Humanos identifica en su segundo apartado, las cláusulas generales que pueden limitar su ejercicio al estar dicha libertad en concurrencia con otros intereses o core rights, por lo que se refiere a una ponderación a través de un test judicial. Con este método, el juez europeo se encarga de practicar el denominado triple test de proporcionalidad, a través del cual decidirá si las medidas adoptadas por las autoridades estatales son legales, legítimas, necesarias en una sociedad democrática, y si las actuaciones llevadas a cabo guardan una relación de proporcionalidad coherente en relación el fin u objetivo perseguido por las mismas.

Las personas creyentes y los grupos de creyentes deben soportar la crítica feroz y la sátira hiriente como se establece en Handyside desde 1976, pero el ateísmo y el agnosticismo, sin embargo, pueden beneficiarse de la protección que recibe la libertad religiosa. Así, el estatus de refugiado en el Reino Unido de un hombre musulmán que se había convertido al ateísmo, y temía que a su regreso a Afganistán fuese perseguido.

Por el contrario, como herramienta de Paz, la libertad religiosa puede ser un motivo suficiente y razonable para no interferir en la libertad de expresión. Así, en Canadá sorprende el caso Owens v. Saskatchewan, muy distinto a lo que está sucediendo en España, donde la predicación desde el púlpito se ha convertido en una actividad de alto riesgo. Owens era acusado por el hecho de reproducir en un newspaper, pasajes de la Biblia en los que se condenaba a los homosexuales y debían pagar con la muerte. La corte de apelación no encontró que Owens contravenía la provisión del hate speech porque sus afirmaciones respondían a convicciones sinceras y de buena fe (bona fide), en el ejercicio de su libertad religiosa y de expresión.

En el hate speech, la revisión de los casos cuando se produce un abuso del Derecho, no exige analizar el contenido. Hablamos del negacionismo, en el que se aplica el lema: «no hay libertad para los enemigos de la libertad». Esta doctrina se sigue de un modo u otro en distintos continentes, así que hablaremos de Oceanía y América. 
Fuera, por tanto, del ámbito europeo, a veces hay una gran distancia entre los pronunciamientos, si se trata de un ámbito educativo o de la prensa. Siendo el mismo contenido repugnante, el fallo puede depender del público al que va dirigido. Como herramienta para prevenir el odio, es justo que se proteja a los menores en el ámbito educativo, pero el discurso antisemita o antirreligioso que sea vejatorio tampoco debería tolerarse ni entre adultos, en la propuesta de limpiar al mundo de una raza o de una religión.

En el caso $R v$. Keegstra, la Corte Suprema de Canadá dictaminó por una escasa mayoría que hubo incitación al odio por parte de un profesor en la High School que enseñaba que el Holocausto nunca tuvo lugar y que los judíos habían creado el mito para ganar simpatía. Una parte de los jueces consideraba que se infringía la libertad de expresión de Keegstra, y mientras otra decidía que la libertad de expresión se puede limitar si está justificadamente demostrado en una sociedad libre y democrática.

Por el contrario, en R. v. Ahenakew, Canadá no le condenó por incitación al odio al decir que el Holocausto fue un remedio para curar una enfermedad, y limpiar al mundo. Después de un largo itinerario procesal, la corte provincial de Saskatchewan, Wilfred Tucker, absolvió a Ahenakew porque sus declaraciones, aunque «repugnantes, desagradables y falsas», no demostraron la intención de incitar al odio. Siguiendo esta línea, se ha derogado el art. 13 de la ley de derechos humanos que castigaba el discurso de odio por teléfono o por internet.

Otra herramienta jurídica es la de la protección del ejercicio libre y público de la religión, especialmente cuando son grupos pequeños y se puede asfixiar su vida.

Argentina aplicó el derecho de réplica reconocido en el art. 14 de la Convención Americana de Derechos Humanos, considerando que la réplica formaba parte del juego de un sistema pluralista. Me refiero al caso en que la Virgen fue insultada en un programa de televisión. Quedó demostrado que debido a la extraordinaria difusión de los mass media, la presentación ridícula, de mofa y vejatoria de ciertas personas, símbolos y dogmas que nutren la fe de éstas, podría dar lugar a sentir una coacción moral a su libre y público ejercicio de la religión, causando un razonable temor por el poder de los medios de comunicación (Ekmedjian v. Sofovich).

Por su parte, en la legislación penal de Canadá se reconoce el poder de las palabras para mutilar, destruir. De ahí que se haga un llamamiento a la supresión de la promoción fácil del odio contra grupos identificables, lo que no es lo mismo que difamación de las religiones, sin embargo, aunque 
no se admite un delito de difamación según el TS de Canadá, se hace una excepción cuando se vaya contra un grupo muy pequeño y pueda suponerle perjuicios demostrables, así en Bou Malhab v. Diffusion Metromedia CMR, Inc. Estamos en la era de la protección de las minorías. Michael McConnell, académico y exjuez federal de los Estados Unidos afirma que: «Es difícil encontrar un caso en cualquier parte del mundo donde se castigue el discurso que apoya a las ideologías dominantes con el objetivo de proteger a los débiles», pues bien, esta sentencia es uno de esos casos excepcionales.

Otra herramienta de paz contra el delito de odio es la unión de las Religiones en su causa. En Argentina hemos apreciado algunas herramientas de paz. En este país la blasfemia no es un delito, y aunque sí se penaliza el discurso de odio, no se admite la censura previa, ni tampoco se castiga como ofensa a los sentimientos, una exposición en una galería como trabajo artístico, tal y como ocurrió en un caso ante la Corte autónoma de Buenas Aires, en el que se cuestionaba la ofensa de sentimientos católicos, pues bien, como herramienta de Paz Religiosa, se acordó un ayuno en reparación de la ofensa causada por la exposición, a iniciativa de las organizaciones protestantes, judías e islámicas.

En contraste, no es una herramienta de paz que los líderes religiosos ataquen a personas ateas u otros estilos de vida, como en la STEDH Günduz c. Turquía, en la que se amparó al líder de una secta islámica que, en la televisión, llamó bastardos a los hijos nacidos de un matrimonio civil, e insultó a toda sociedad democrática y laica, por no imponer la Sharia.

Tampoco se previene el delito de odio ni se promueve la paz y el diálogo si las religiones se atacan unas a otras. Australia no restringe el discurso religioso por leyes de blasfemia, herejía o apostasía. El código penal de la Commonweath castiga el delito de sedición de un grupo por usar la fuerza o violencia contra otro grupo por razón de religión, lo que podría amenazar la paz, el orden o el buen gobierno de Australia.

Algunos estados de Australia como Queensland, Tasmania y Victoria tienen leyes de vilipendio religioso o leyes de discurso religioso. En Victoria hay una ley de tolerancia religiosa y racial, y una ley de antidiscriminación.

En la Ley de Victoria se establece que no se puede cargar contra una persona por delito de vilipendio religioso si su comportamiento es razonable y de buena fe, o se conduce en el curso de un trabajo o exposición artística, si tiene propósitos genuinamente académicos, artísticos, religiosos o científicos, o si persigue algún otro interés público. 
En este país es conocido el caso Islamic Council of Victoria v. Catch the Fire Ministries, Inc. El Consejo Islámico consideraba que Catch the Fire, un Iglesia cristiana adventista había causado un vilipendio religioso al organizar un seminario, publicar un newsletter, y un artículo en su página web, en los que se atacaba a la fe islámica, lo que además iba en contra del art. 9 de la ley de tolerancia religiosa y racial. Catch the Fire aducía que su propósito era genuinamente religioso y que perseguía el interés público. El tribunal administrativo y civil de Victoria respaldó la demanda del Consejo Islámico, pero Catch the Fire apeló exitosamente, y esta decisión fue mantenida por el Tribunal Supremo de Victoria en 2006.

Catch the Fire inspira también la Decisión del Tribunal Civil y Administrativo de Victoria de 19 de julio de 2016, que rechaza la denuncia de un musulmán por grave difamación religiosa en el artículo de un periódico. El denunciado, the Herald E Weekly Times, Ltd., publicó un artículo en primera página titulado: «Islam must change», escrito por Ellen Whinnett, trabajo que fue publicado después de los ataques terroristas de noviembre de 2015 en París. Aunque el aprendizaje de buenas prácticas por los periodistas, y los medios de comunicación en general, sea una ventajosa herramienta; en este caso y, con esto finalizo mi discurso, sí que apreciamos la necesidad de otra herramienta, y es que el diálogo entre las religiones y entre éstas, el poder político y la sociedad, debe aceptar la crítica constructiva, siempre que no sea cimiento de vejación, solo así la religión será contemplada como contribución al bien común y no como un problema. 